\title{
Case of late hematoma after breast augmentation
}

\author{
Leslie Kim ${ }^{1}$, Nikki Castel ${ }^{2}$, Fereydoun Don Parsa ${ }^{1}$ \\ ${ }^{1}$ Division of Plastic Surgery, Department of Surgery, University of Hawaii, John A. Burns School of Medicine, Honolulu, HI; ${ }^{2}$ Division of \\ Plastic Surgery, Department of Surgery, Rutgers New Jersey Medical School, Newark, NJ, USA
}

We present a case report of a patient who experienced a late, spontaneous breast hematoma 26 years after primary breast augmentation. Late hematomas are a rare complication of breast augmentation with uncertain etiology. In this case, there was no trauma, calcifications, or implant rupture. We believe the patient's hematoma was secondary to erosion of a capsular vessel due to capsular contracture.

\author{
Correspondence: Fereydoun Don Parsa \\ Division of Plastic Surgery, \\ Department of Surgery, University of \\ Hawaii, John A. Burns School of \\ Medicine, 651 Ilalo Street, Honolulu, \\ HI 96813, USA \\ Tel: +1-808-526-0303 \\ Fax: +1-808-536-8836 \\ E-mail:fdparsa@gmail.com
}

Keywords Breast implants / Contracture / Hematoma

Received: 5 Oct 2016 • Revised: 14 Jan 2017 • Accepted: 7 Jun 2017

pISSN: 2234-6163 • elSSN: 2234-6171 • https://doi.org/10.5999/aps.2016.01718• Arch Plast Surg 2018;45:177-179

\section{INTRODUCTION}

Bleeding is a well-known and well-characterized acute complication following breast augmentation. This occurs in about $1 \%$ of patients [1-3]. Acute hematoma incidence is not significantly associated with type of implant surface texture or type of surgical procedure [2]. Conversely, late hematomas are a very rare complication of breast augmentation, documented by only 15 20 case reports. Here we describe a case in which capsular contracture appears to have contributed to the development of a late hematoma, in the absence of trauma, calcification, or implant rupture.

\section{CASE}

A 58-year-old woman, gravida 2 para 2, underwent a bilateral subglandular breast augmentation in August 1990 with polyurethane-coated, $325 \mathrm{~mL}$ silicone gel Replicon implants via inframammary incisions. The patient's postoperative course was uneventful. The patient had soft breasts until 2011, when she began to experience capsular contractures bilaterally. A mammo- gram from 2015 suggested rupture of the right implant. In May 2016 , the patient began to experience a gradual increase in size and distortion of the right breast, which was associated with mild pain. On physical examination, the patient had evidence of bilateral capsular contracture, Baker IV on the right and Baker III on the left. The right breast was firm and deformed (Figs. 1, 2 ). There were no palpable masses or lymphadenopathy.

In May 2016, the patient underwent bilateral implant exchange with total capsulectomies. The capsule on the right was darkly pigmented and $150 \mathrm{~mL}$ of uncoagulated dark blood was evacuated from the capsule (Fig. 3). The implant was removed intact and total capsulectomy was performed. The capsule was strongly adherent to surrounding tissues and difficult to excise. There was an area of erosion in the medial aspect of the capsule as shown in Fig. 4. No calcifications were noted. The old implants were exchanged for $322 \mathrm{~mL}$ textured gel implants (Allergan).

The capsule on the left was pale and no blood or fluid collections were noted. The implant was removed intact and total capsulectomy was performed without difficulty. The left capsule was barely adherent to the underlying pectoralis muscle and 


\section{Fig. 1. Front view of the hematoma}

Front view of the hematoma shows the swelling of the upper pole of the right breast with mild bluish discoloration.

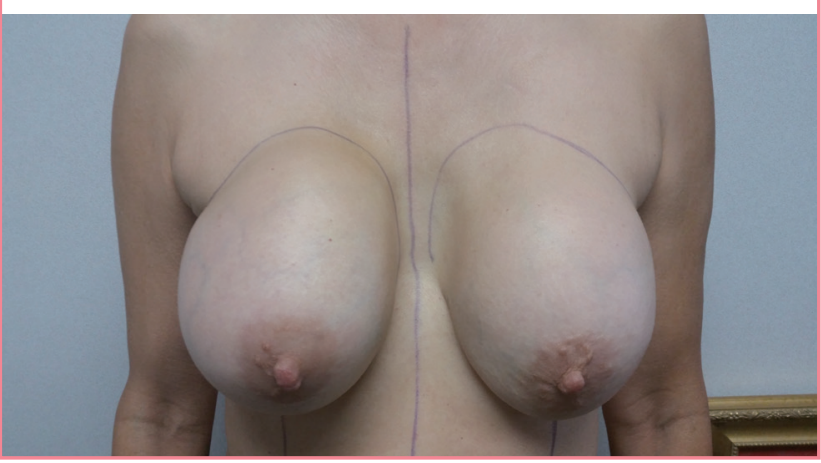

\section{Fig. 2. Lateral view of the hematoma}

Right lateral view of same patient shown in Fig. 1.

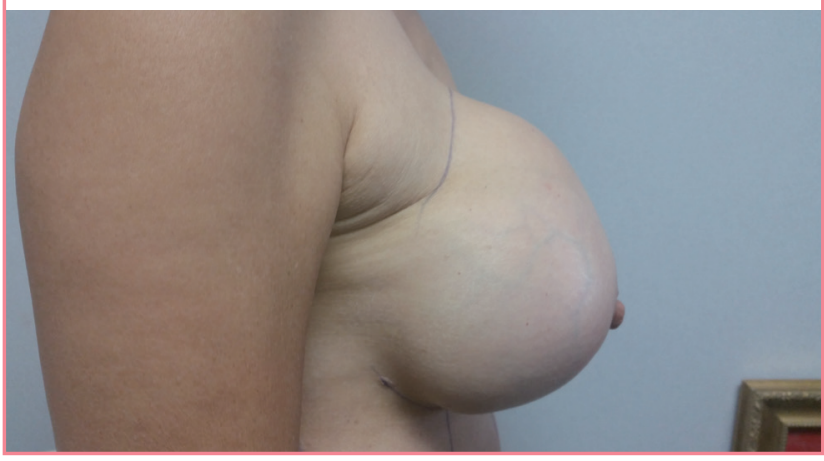

Fig. 3. Right opened capsule

The right capsule has been opened with a stab incision, demonstrating outflow of uncoagulated blood.

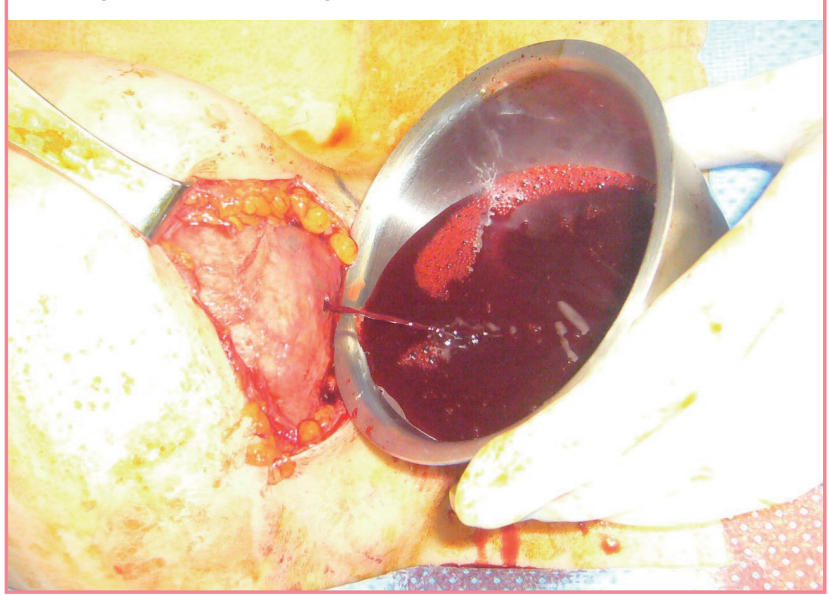

overlying breast tissue. It was easy to excise with minimal blood loss. The removed capsule, shown in Fig. 5, showed mild capsular calcifications primarily involving the anterior surface of the implant.

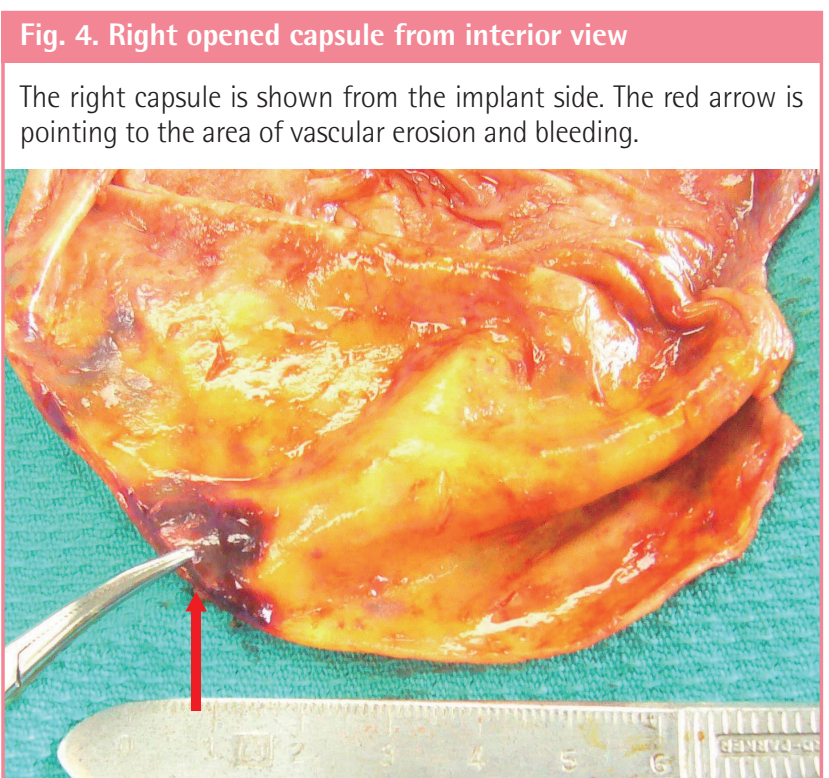

Fig. 5. Left opened capsule

The left breast capsule as seen from inside. The hemostat points to a limited area of calcification on the anterior surface. No vascular erosion or bleeding were noted.

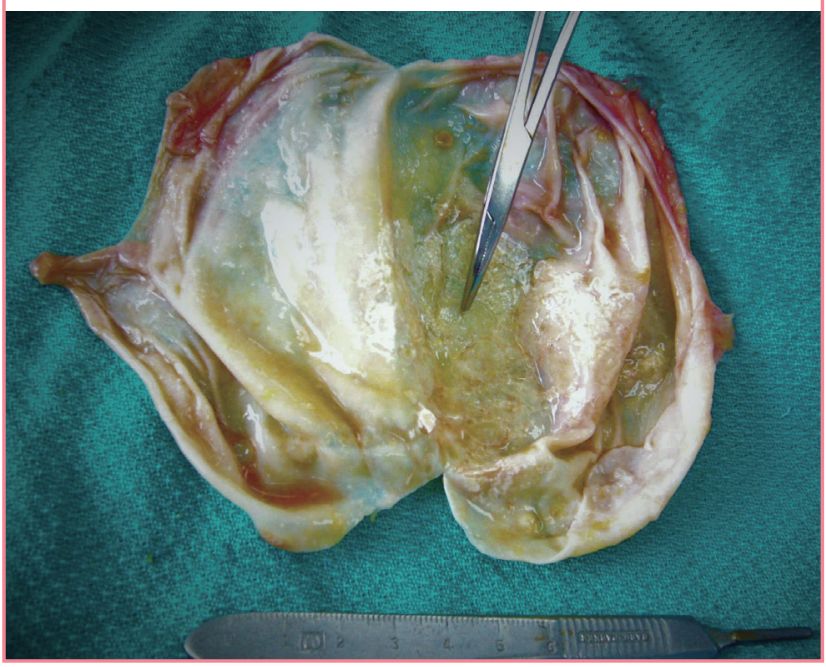

\section{DISCUSSION}

Late complications of breast augmentation with implants are varied, but fairly rare, including anaplastic large T-cell lymphoma, late seroma, and late hematoma. They often present as late progressive enlargement or deformation of the affected breast [4-7]. The late complications of breast augmentation with implants are varied, but fairly rare, including anaplastic large cell lymphoma, late seroma, and late hematoma. The etiology of late hematoma following breast augmentation has been poorly characterized due to its rarity. The first case was reported by Georgiade et al. [8] in 1979. They proposed that corticosteroid usage 
at time of placement was responsible for the erosion and subsequent hematoma. Currently, general consensus holds that late hematomas most likely result from erosion of capsular vessels due to trauma, inflammation, microfracture of the capsule, or friction of implant against the capsule [9-12]. In one case, trau$\mathrm{ma}$ in the form of amorous squeezing was implicated [13]. In this case report, capsular contracture appears to have been the primary mechanism for the late hematoma. Previous case reports have suggested that polyurethane coating, as in this case, may provoke an intense inflammatory reaction which would subsequently place patients at higher risk for developing capsular contracture and, possibly, late hematoma [9]. However, it has since been shown that polyurethane-coating actually decreases the risk of capsular contracture development [14]. In this patient, gradual disintegration of the protective polyurethane coating may have contributed to the development of capsular contracture, culminating in late hematoma development 26 years later due to pressure against capsular vessels (Fig. 4).

In conclusion, polyurethane-coated implants have been discontinued in the United States since 1992, however, they are still present in a number of patients. Though polyurethane coating is protective against capsular contracture, as the coating ages and disintegrates, many more patients may begin presenting with complaints of capsular contracture. In rare cases, they may also present with late hematoma likely due to capsular vascular erosion.

\section{NOTES}

\section{Conflict of interest}

No potential conflict of interest relevant to this article was reported.

\section{Ethical approval}

The study was performed in accordance with the principles of the Declaration of Helsinki. Written informed consents were obtained.

\section{Patient consent}

The patients provided written informed consent for the publication and the use of their images.

\section{REFERENCES}

1. Duxbury PJ, Harvey JR. Systematic review of the effective- ness of polyurethane-coated compared with textured silicone implants in breast surgery. J Plast Reconstr Aesthet Surg 2016;69:452-60.

2. Handel N, Cordray T, Gutierrez J, et al. A long-term study of outcomes, complications, and patient satisfaction with breast implants. Plast Reconstr Surg 2006;117:757-67.

3. Hidalgo DA, Spector JA. Breast augmentation. Plast Reconstr Surg 2014;133:567e-583e.

4. Jewell M, Spear SL, Largent J, et al. Anaplastic large T-cell lymphoma and breast implants: a review of the literature. Plast Reconstr Surg 2011;128:651-61.

5. Hall-Findlay EJ. Breast implant complication review: double capsules and late seromas. Plast Reconstr Surg 2011;127:5666.

6. Peters W, Fornasier V, Howarth D. Late unilateral hematoma after breast augmentation. Plast Surg (Oakv) 2014;22: 18-21.

7. Peters W. Update on anaplastic large cell lymphoma in women with breast implants. Plast Surg (Oakv) 2014;22: 267-9.

8. Georgiade NG, Serafin D, Barwick W. Late development of hematoma around a breast implant, necessitating removal. Plast Reconstr Surg 1979;64:708-10.

9. Hsiao HT, Tung KY, Lin CS. Late hematoma after aesthetic breast augmentation with saline-filled, textured silicone prosthesis. Aesthetic Plast Surg 2002;26:368-71.

10. Gorgu M, Aslan G, Tuncel A, et al. Late and long-standing capsular hematoma after aesthetic breast augmentation with a saline-filled silicone prosthesis: a case report. Aesthetic Plast Surg 1999;23:443-4.

11. Mauro S, Eugenio F, Roberto B. Late recurrent capsular hematoma after augmentation mammaplasty: case report. Aesthetic Plast Surg 2005;29:10-2.

12. Brickman M, Parsa NN, Parsa FD. Late hematoma after breast implantation. Aesthetic Plast Surg 2004;28:80-2.

13. van Rijssen AL, Wilmink H, van Wingerden JJ, et al. Amorous squeezing of the augmented breast may result in late capsular hematoma formation: a report of two cases (and a review of English-language literature on late hematoma formation in the augmented breast). Ann Plast Surg 2008;60: 375-8.

14. Castel N, Soon-Sutton T, Deptula P, et al. Polyurethanecoated breast implants revisited: a 30-year follow-up. Arch Plast Surg 2015;42:186-93. 